\title{
Eksplorasi Etnomatematika pada Masjid Al-Alam Marunda Ditinjau dari Segi Geometri
}

\author{
Muhammad Faturrahman ${ }^{1}$, Slamet Soro ${ }^{2}$ \\ ${ }^{1,2}$ Pendidikan Matematika, Fakultas Keguruan dan Ilmu Pendidikan, Universitas Muhammadiyah Prof. Dr. HAMKA \\ Jl. Tanah Merdeka No 20, Jakarta Timur, Indonesia \\ faturroom@gmail.com
}

\begin{abstract}
Learning mathematics in today's era places more emphasis on the aspect of understanding mathematical concepts to solve mathematical problems. Ethnomathematics is an approach to learning mathematics that is linked to culture. Geometric concepts in the form of historic buildings can be observations produced by culture. Each area has its own historical buildings. In Jakarta, there is a historic building, namely the Al-Alam Marunda Mosque which was built in 1900 AD. The purpose of this study is to explore the geometric concepts contained in the Al-Alam Marunda Mosque, so that they can be used as learning resources in learning mathematics. This type of research is a qualitative research with an ethnographic approach. Data was collected by means of observation, interviews, literature studies, documentation, and questionnaires. The instruments used in the form of observation guidelines, interview guidelines, diaries, and questionnaires, then it can be concluded that the geometric concepts contained in the Al-Alam Marunda Mosque are the concept of flat wake, wake up space, and the concept of reflection transformation. Ethnomathematics can contain aspects of understanding mathematical concepts with objects that are seen in real terms.
\end{abstract}

Keyword: Ethnomathematics, Geometric, Al-Alam Mosque

\begin{abstract}
Abstrak
Pembelajaran matematika di zaman sekarang lebih menekankan pada aspek pemahaman konsep matematis untuk menyelesaikan masalah matematika. Etnomatematika dapat menjadi pendekatan pembelajaran matematika untuk memfasilitasi kemampuan pemahaman konsep matematis. Konsep-konsep geometri pada bentuk bangunan bersejarah dapat menjadi pengamatan yang dihasilkan oleh budaya. Setiap daerah memiliki bangunan bersejarah masing-masing. Di Jakarta terdapat bangunan bersejarah yaitu Masjid Al-Alam Marunda yang dibangun sejak tahun 1900 masehi. Tujuan penelitian ini adalah untuk mengeksplorasi konsep geometri yang terdapat pada Masjid AlAlam Marunda, sehingga dapat dijadikan sumber belajar dalam pembelajaran matematika. Jenis penelitian ini adalah penelitian kualitatif dengan pendekatan etnografi. Pengumpulan data dilakukan dengan cara metode observasi, wawancara, studi literatur, dokumentasi, dan angket. Instrumen yang digunakan berupa pedoman observasi, pedoman wawancara, catatan harian, dan angket, kemudian dapat disimpulkan bahwa konsep geometri yang terdapat pada Masjid Al-Alam Marunda adalah konsep bangun datar, bangun ruang, dan konsep transformasi refleksi. Etnomatematika dapat memuat aspek pemahaman konsep matematis dengan objek yang dilihat secara nyata.
\end{abstract}

Kata kunci: Etnomatematika, Geometri, Masjid Al-Alam

Copyright (c) 2021 Muhammad Faturrahman, Slamet Soro

$\triangle$ Corresponding author: Muhammad Faturrahman

Email Address: faturroom@gmail.com (Jl. Tanah Merdeka No. 20, Jakarta Timur, Indonesia)

Received 21 June 2021, Accepted 02 July 2021, Published 12 Juli 2021

\section{PENDAHULUAN}

Pada beberapa bidang ilmu pengetahuan untuk membantu memecahkan masalah, matematika menjadi ilmu dasar yang dapat diterapkan sebagai alat bantu. Beberapa alasan tentang perlunya pendidikan matematika untuk ditanamkan kepada peserta didik, diantaranya adalah agar peserta didik dapat berpikir logis dan deduktif, serta dapat memecahkan masalah pada kehidupan sehari-hari dan mengembangkan kreatifitas. Faktor yang dirasa cukup berpengaruh dalam pendidikan matematika adalah kualitas guru sebagai pendidik(M. Gay, 2015). Selaras dengan menurut Sundari bahwa pendidikan yang 
bermutu tidak akan terwujud tanpa adanya guru sebagai pendidik yang berkualitas dan mempunyai peran penting dalam kecerdasan setiap peserta didik(F. Sundari, 2017). Oleh karena itu kualitas guru memiliki peranan yang penting dalam proses belajar mengajar(M. Ja'far, Sunardi, 2014), serta sumber belajar matematika menjadi objek yang penting lainnya karena kebutuhan pada pembelajaran matematika di zaman sekarang lebih menekankan pada aspek pemahaman konsep matematis untuk menyelesaikan masalah matematika (R. Purwasih 2015). Pendidik mempunyai pengaruh besar dalam membuat batasbatas antara dua bidang yaitu matematika yang formal atau matematika yang ada di sekolah dan kegiatan matematika dalam kehidupan sehari-hari atau diluar sekolah.(Pertiwi \& Budiarto, 2020) Sehingga guru perlu meningkatkan kemampuan dalam mengelola sumber belajar, salah satunya bisa menerapkan sumber belajar matematika dengan pendekatan budaya.

Etnomatematika merupakan ilmu pengetahuan yang mengkaji tentang perpaduan antara budaya dan matematika. Ilmu pengetahuan ini sudah lama menjadi pembahasan sejak pertama kali diperkenalan oleh D’Ambrosio, seorang matematikawan asal Brazil. Pendapat D'Ambrosio terkait etnomatematika yaitu penggunaan matematika dari sekelompok budaya yang dapat diidentifikasi dan dapat dianggap sebagai suatu studi dari matematika yang ditemukan dalam berbagai budaya. (D’Ambrosio, 1985)(Rosa, 2011). Kemudian Rachmawati (2012) mendefinisikan etnomatematika sebagai cara-cara khusus yang dipakai oleh suatu kelompok budaya atau masyarakat tertentu dalam aktivitas matematika. Aktivitas matematika yang dimaksud adalah aktivitas yang didalamnya terjadi proses pengabstraksian dari pengalaman nyata dalam kehidupan sehari-hari kedalam matematika atau sebaliknya. Aktivitas tersebut dapat dijumpai pada kehidupan sehari-hari, seperti penggunaan konsep-konsep geometri dalam arsitektur rumah-rumah adat atau bangunan bersejarah, konsep-konsep aritmetika sosial dalam perdagangan, konsep-konsep aritmetika sederhana dalam permainan anak-anak, dan lain-lain. Hal ini menunjukkan bahwa konsep-konsep matematika telah dipahami oleh masyarakat di masa lampau dan diterapkan dalam konsep budaya.

Salah satu terapan yang dapat menjadi pengamatan dihasilkan oleh budaya adalah bangunan bersejarah. Masjid Al-Alam Marunda merupakan bangunan bersejarah terletak di kecamatan Cilincing, kota Jakarta Utara seperti yang dapat dilihat pada Gambar 1. Bentuk bangunan dari masjid masih dijaga keasliannya sampai sekarang. Masjid Al-Alam dapat dianalisis dan ditelaah dalam konsep-konsep matematika terkhusus geometri karena memiliki bentuk struktur bangunannya yang berkaitan dengan geometri.

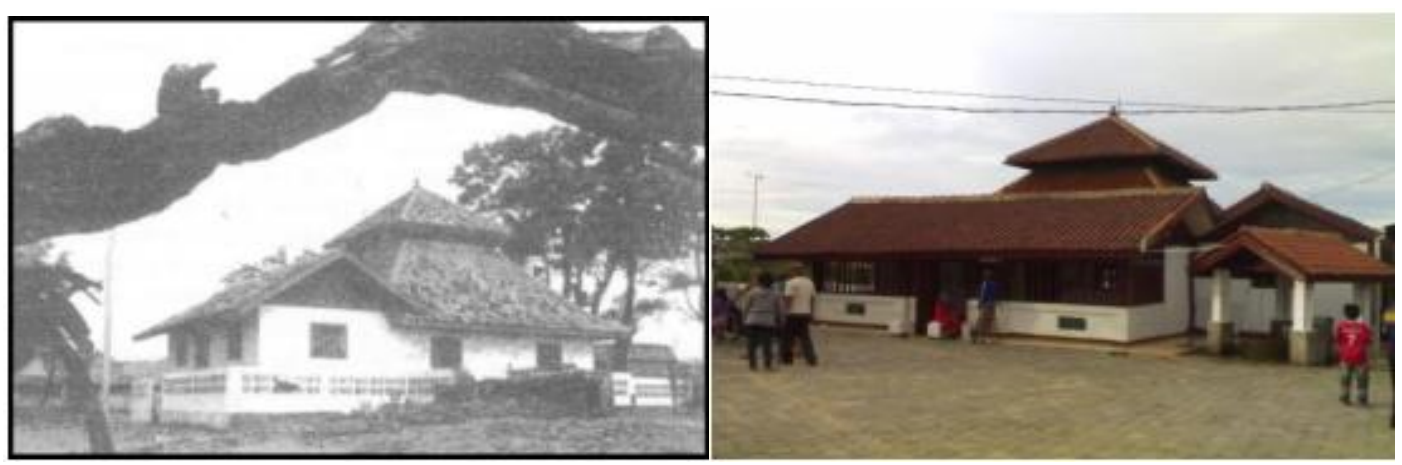

Gambar 1. Gambar Masjid Al-Alam pada zaman Belanda (kiri) dan pada tahun 2020 (kanan) 
Geometri merupakan salah satu cabang matematika yang bersifat abstrak. Geometri dalam matematika mempelajari titik, garis, sudut, bidang, ruang, dan dua bentuk bangun yaitu bangun datar dan bangun ruang (Hamzah, A., 2014). Pembelajaran geometri membutuhkan banyak contoh-contoh kontekstual agar dipahami dengan lebih mudah. Seperti menggambarkan konsep matematika dari visualisasi gambar yang nyata, sketsa gambar, atau bentuk-bentuk bangunan yang dapat dilihat secara konkret dalam keseharian (Yulianti, 2016).Dengan memahami konsep geometri, maka setiap orang mendapatkan bantuan dalam menggambarkan dan memvisualisasikan bentuk-bentuk di kehidupan nyata.

Hal tersebut sesuai dengan penelitian oleh Rani, diketahui bahwa dalam situs bangunan Candi Ratu Boko terdapat beberapa bangunan yang memiliki keterkaitan dengan matematika, salah satunya pada konsep geometri bangun datar seperti segitiga, persegi, persegi panjang, trapesium, jajargenjang dan lingkaran (Rani, 2018). Dalam hal ini etnomatematika berperan sebagai sumber belajar yang menjembatani antara konsep abstrak matematika dengan objek konkret dalam memvisualisasikan secara nyata. Kemudian penelitian yang dilakukan oleh Yulianti menunjukkan bahwa perangkat berbasis etnomatematika untuk pembelajaran matematika pada materi geometri menggunakan Candi Borobudur memperlihatkan hasil observasi keterlaksanaan pembelajaran menunjukkan presentase rata-rata 79,68\% dengan pelaksanaan pembelajaran yang telah dikembangkan memenuhi kriteria cukup (Yulianti, 2016).

Penelitian ini bertujuan untuk mendeskripsikan hasil ekplorasi bentuk etnomatematika dan aspek historis pada Masjid Al-Alam Marunda, serta mendokumentasikan bangunan Masjid. Dengan etnomatematika diharapkan peserta didik dapat lebih mengeksplor kemampuan metakognitif, berpikir kritis dan kemampuan pemecahan mereka masing-masing. Dengan hal demikian, etnomatematika dapat dilihat dari objek nyata sehari-hari sehingga memudahkan peserta didik untuk lebih menggambarkan secara langsung ke dalam pikirannya (Sarwoedi, Marinka, D. O., Febriani, P., \& Wirne, 2018). Maka tujuan penelitian ini juga untuk melakukan eksplorasi dan analisis terkait geometri dari bangunan Masjid Al-Alam Marunda yang kemudian dapat digunakan sebagai sumber belajar dan pengetahuan terkait dengan objek pengamatan secara nyata pada pembelajaran matematika materi geometri.

\section{METODE}

Penelitian ini menggunakan penelitian secara kualitatif dengan metode pendekatan etnografi. Pendekatan etnografi adalah kajian mengenai kehidupan dan budaya suatu masyarakat atau etnik, misalnya tentang adat-istiadat, kebiasaan, hukum, seni, religi dan bahasa(Andarini et al., 2019). Etnografi merupakan suatu bentuk penelitian yang terfokus pada makna sosiologis diri individu dan konteks sosial budayanya yang dihimpun melalui observasi lapangan sesuai dengan fokus penelitian (Yusuf, 2014). Pada hal ini etnografi dikaitkan tentang bagaimana sejarah dan bentuk dari bangunan objek yang diamati. Penelitian ini digunakan untuk mengeksplor informasi tentang etnomatematika yang meliputi konsepkonsep matematika khususnya geometri yang ada pada Masjid Al-Alam Marunda. Informan dalam penelitian ini adalah ketua pengurus Masjid yaitu bapak H. Abu Hasan Ashari, dan marbot Masjid bapak Koesnadi. Data dapat dikumpulkan melalui wawancara, observasi, pencatatan, studi literatur, angket, dan 
dokumentasi. Analisis yang dilakukan yaitu menganalisis bentuk matematika dan mengelompokkannya sesuai dengan konsep geometri matematika yang ada.

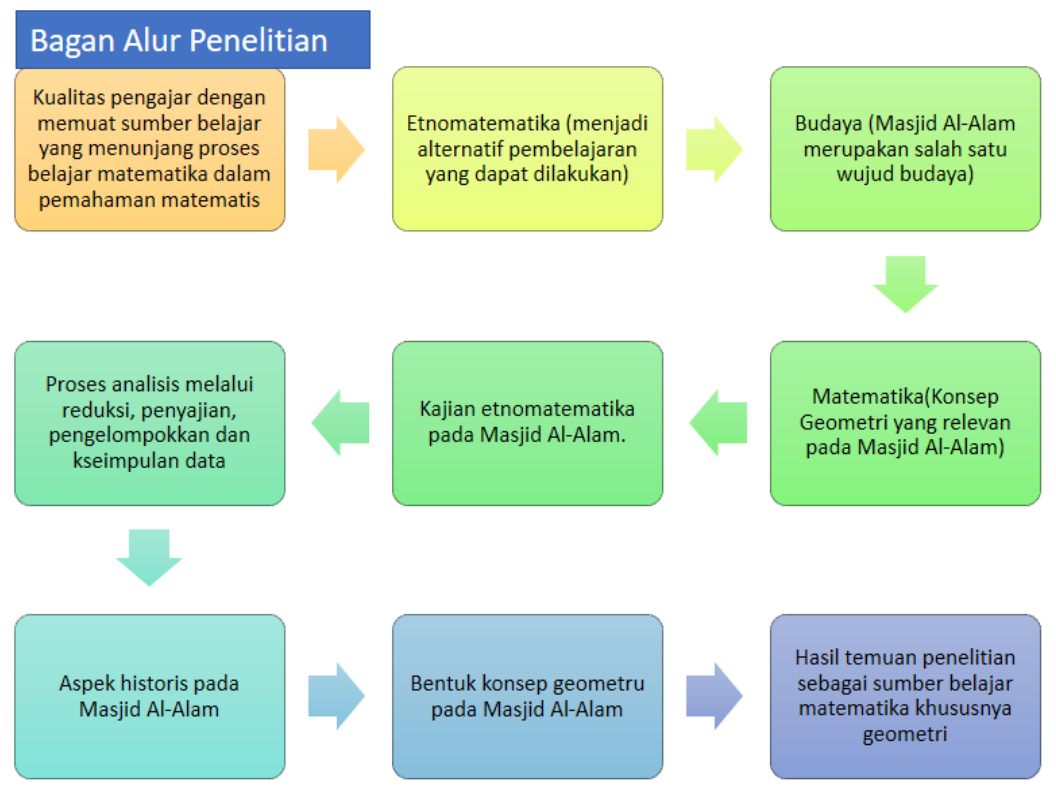

Gambar 2. Road Map Penelitian

\section{HASIL DAN DISKUSI}

Berdasarkan dari hasil eksplorasi melalui studi literatur, wawancara, dan observasi, Masjid AlAlam Marunda yang sudah dibangun dari tahun 1900 Masehi merupakan bangunan bersejarah terletak di Jalan Marunda No.1, RT 003 RW 07 Marunda, Cilincing, Jakarta Utara, atau tepatnya di pinggiran Pantai Marunda. Pada tahun 1975 Pemerintah Provinsi DKI Jakarta menetapkan masjid yang memiliki peranan penting dalam penyebaran Agama Islam di Tanah Jawa ini sebagai Bangunan Cagar Budaya. Terdapat dua versi sejarah yang berkembang dalam masyarakat, terkait kapan dan siapa tepatnya pendiri masjid ini sesungguhnya. Ada yang mengkaitkannya dengan para wali Allah yang mendirikan masjid hanya dalam waktu satu malam, ada juga yang menghubungkannya dengan penyerangan Pasukan Fatahillah ke Pelabuhan Sunda Kelapa. Fatahillah memilih muara Sungai Cilincing sebagai markas perjuangan sekaligus menjadi basis pertahanannya. Di tempat inilah mereka membangun masjid dan surau sebagai sarana ibadah. Kelak masjid yang dibangun tersebut di muara sungai tadi dikenal sebagai Masjid Marunda, sedangkan surau menjadi Masjid Al Alam Cilincing. Masjid Al-Alam Marunda dahulu bukan hanya digunakan sebagai tempat ibadah, tetapi digunakan juga sebagai tempat strategi perang oleh pasukan Fatahillah.

Berdasarkan hasil wawancara dengan kedua informan yaitu bapak Abu Hasan dan bapak Koesnadi selaku ketua pengurus dan marbot masjid, beliau menjelaskan bahwa masjid Al-Alam merupakan bangunan bersejarah bagi umat muslim yang dijaga keaslian bentuk bangunannya. Perawatan bangunan masjid dilakukan juga untuk memberikan pelayanan fasilitas bagi para jamaah yang datang untuk beribadah. Bapak Koesnadi menerangkan juga tentang makna dari beberapa bagian pada 
bangunan masjid seperti jumlah empat pilar yang ada pada ruangan utama memiliki makna dari empat khalifah besar islam yaitu Abu Bakar Assiddiq, Umar bin Khattab, Usman bin Affan, dan Ali bin Abu Thalib. selanjutnya makna dari lima tiang yang terdapat pada disetiap jendela masjid adalah tentang sholat fardhu lima waktu yaitu Isya, Subuh, Dzuhur, Ashar, dan Magrib sebagai tiang dari agama islam.
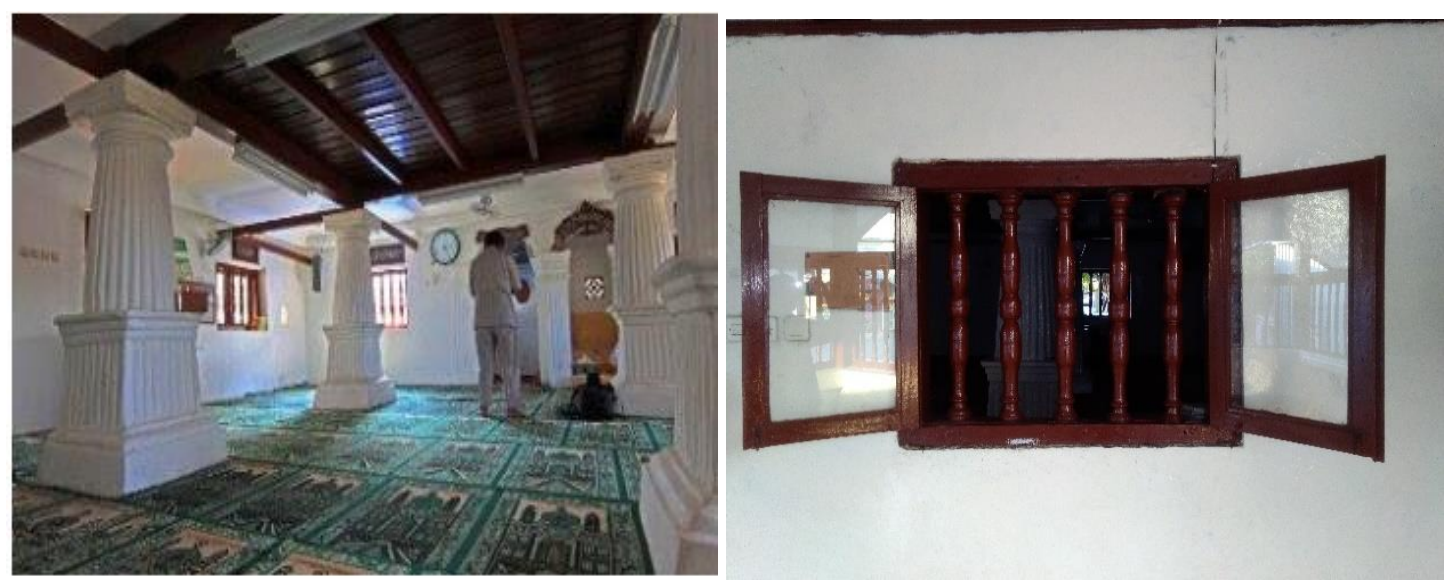

Gambar 2. Empat pilar dan jendela pada Masjid Al-Alam

Berdasarkan hasil eksplorasi, bangunan Masjid Al-Alam dari luar sangat terlihat perpaduan corak betawi dengan arsitektur masjid-masjid di Jawa. Bangunan ini memiliki tembok dari beton dengan cat putih di sisi utara, barat, timur, dan selatan. Dari segi atap, masjid ini memiliki atap berbentuk limas dua tumpang yang terbuat dari genteng. Dengan memiliki tinggi dari langit-langit sampai ke ujung atap 3,5 meter, dan lebar 4 meter untuk bagian atas, serta lebar 8 meter untuk bagian bawah atap.

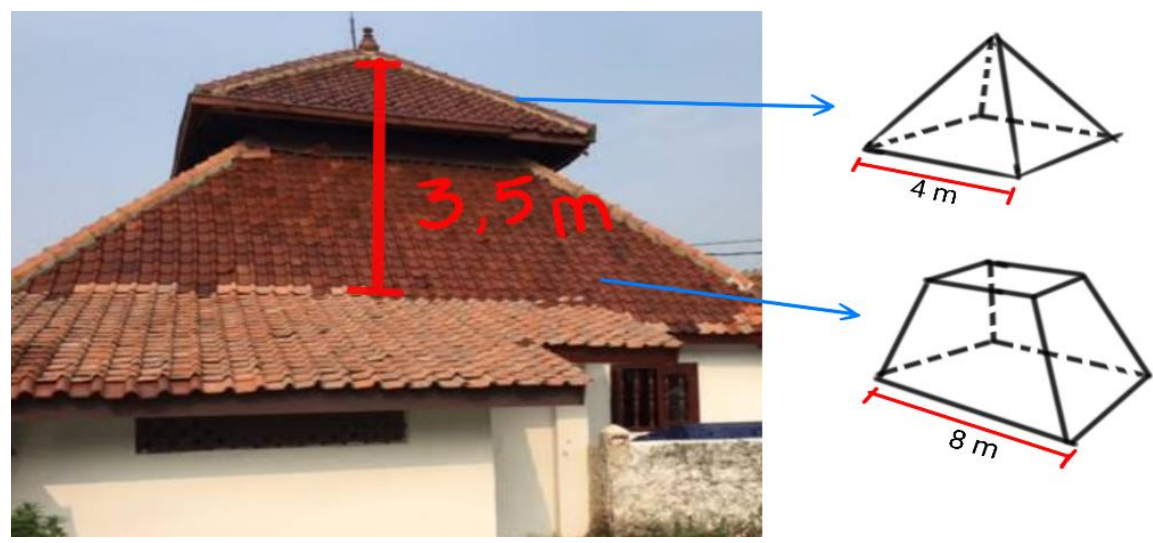

Gambar 3. Atap masjid Al-Alam dan hasil sketsa

Setelah diamati dari segi geometri, bentuk etnomatematika pada atap Masjid Al-Alam mewakili beberapa jenis bangun ruang. Bangun ruang yang dapat diamati yaitu limas yang tegak ke atas dengan alas berbentuk persegi namun tumpang dua sehingga bagian bawahnya terpotong dan tertindih oleh bagian atas atap. Limas merupakan bangun ruang dengan alas berbentuk bidang datar (segi beraturan) dan sisi miringnya berbentuk segitiga sebanyak segi alasnya yang berpotongan pada satu titik. Titik potongan tersebut disebut titik puncak limas. Limas terpancung datar ialah bagian suatu limas yang letaknya antara 
bidang alas dan sebuah bidang yang sejajar dengan alas, serta memotong semua rusuk-rusuk tegaknya. Limas terpancung membentuk bidang-bidang trapesium dengan 6 sisi dan 12 rusuk.

Masjid ini juga memiliki serambi di bagian selatan dan timur. Luas keseluruhan dari ruangan utama hingga serambi adalah $12 \mathrm{~m} \times 12 \mathrm{~m}$. Pada bagian serambi setelah diamati dari segi geometri terdapat kerangka atau penopang atap berukuran panjang 4 meter dan tinggi 1 meter yang mewakili bentuk bangun datar.

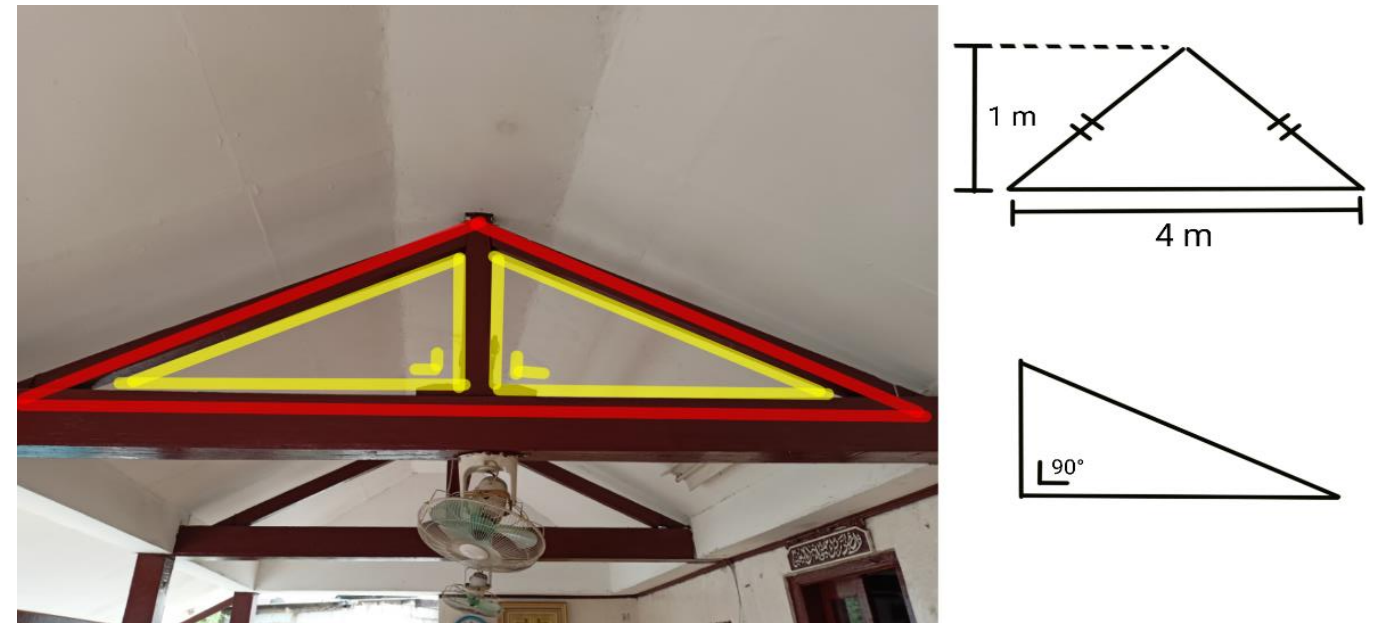

Gambar 4. Kerangka atap serambi dan hasil sketsa

Bangun datar yang dapat diamati yaitu segitiga, hasil eksplorasi selanjutnya dari penopang atap terdapat konsep segitiga sama kaki dan 2 segitiga siku-siku. Segitiga sama kaki adalah segitiga yang memiliki dua sisi dengan panjang yang sama dan dua sudut yang sama, sedangkan segitiga siku-siku memiliki satu sudut siku-siku $90^{\circ}$ yang berhadapan dengan sisi miring, dan dua sisi lain disebut sisi tegak.

Di dalam ruangan utama, terdapat bangunan yang sangat sederhana dan kecil. memiliki ruangan utama berbentuk persegi berukuran $8 \mathrm{~m}$ x $8 \mathrm{~m}$. Tinggi dari lantai ke langit-langit hanya 2,2 $\mathrm{m}$. Dari ruangan ini, dapat ditemukan perpaduan arsitektur dari Eropa, Cina, Jawa, dan Betawi. Ruangan utama masjid setelah diamati dari segi geometri dapat mewakili bentuk bangun ruang yaitu balok. Ruangan utama masjid dapat dilihat pada Gambar 5.
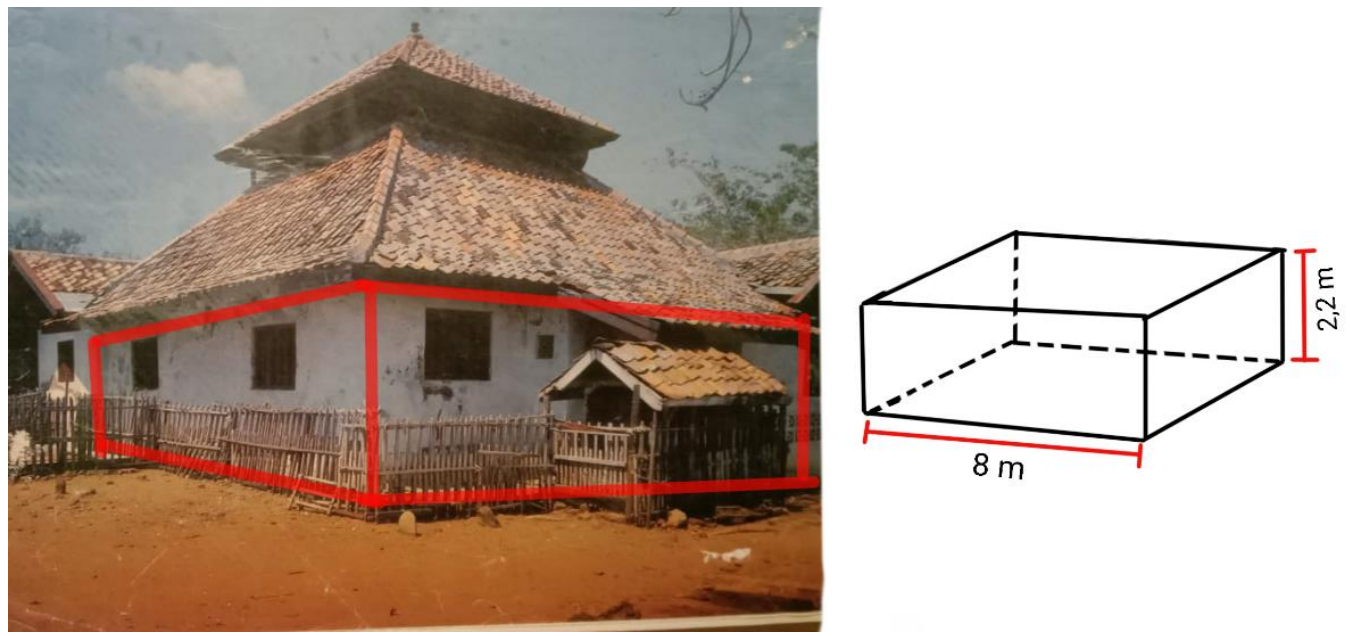

Gambar 5. Ruangan utama masjid dan sketsa 
Balok merupakan bangun ruang yang dibatasi dengan 6 bidang berbentuk persegi atau persegi panjang atau keduanya, terdapat panjang, lebar, dan tinggi, serta 12 rusuk, dan 8 titik sudut.

Dibawah ini adalah gambar pilar yang ada didalam ruangan utama. Dengan tinggi 2, 2 meter dan lebar $50 \mathrm{~cm}$.
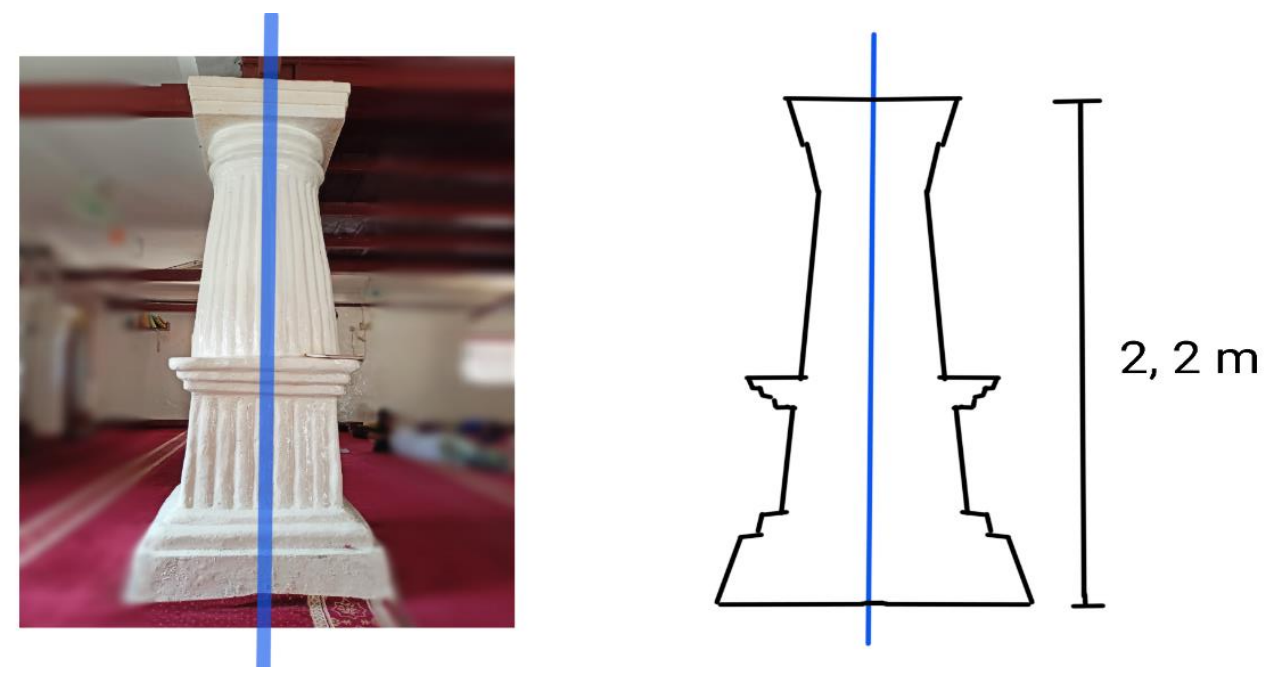

Gambar 6. Pilar didalam masjid Al-Alam

Hasil pengamatan dari segi geometri, bentuk pilar ini mewakili konsep transformasi refleksi seperti yang dapat dilihat pada Gambar 6. Saat diambil satu garis tengah maka sisi kiri akan sama dengan sisi kanan. Refleksi merupakan salah satu transformasi geometri disebut juga pencerminan dari suatu objek dengan ukuran dan jarak yang sama. Di sebelah serambi masjid terdapat sumur memiliki diameter $80 \mathrm{~cm}$ dan tinggi $60 \mathrm{~cm}$, tepat disamping sumur juga terdapat wadah air memiliki panjang $60 \mathrm{~cm}$, lebar $50 \mathrm{~cm}$, dan tinggi $60 \mathrm{~cm}$, yang digunakan untuk mengambil air wudhu.

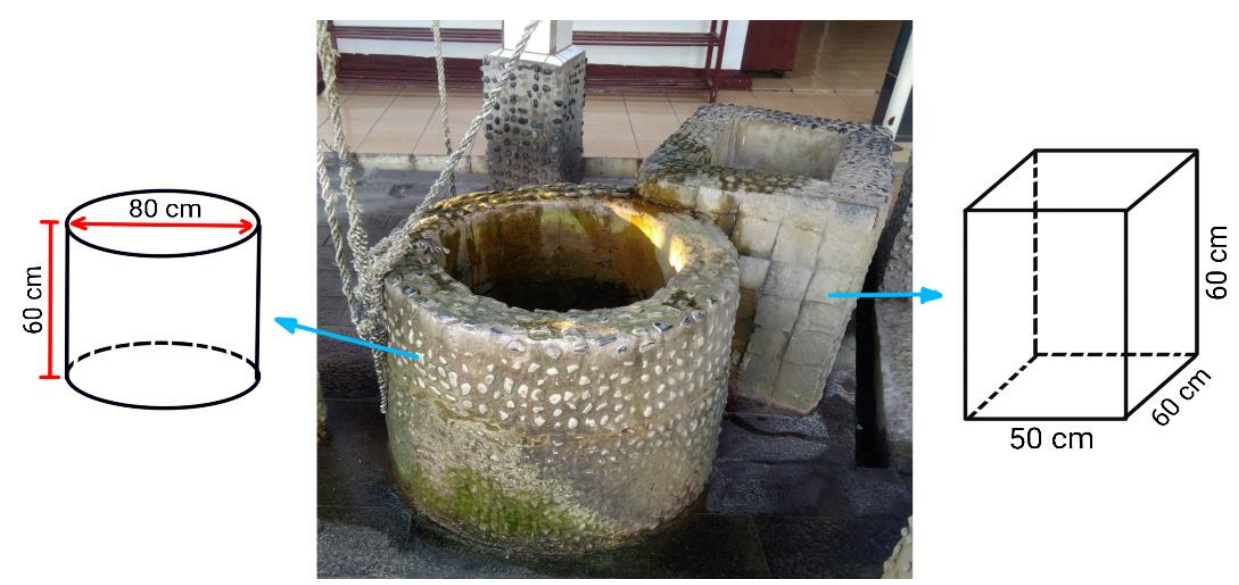

Gambar 7. Sumur dan wadah air

Hasil pengamatan dari segi geometri, bentuk sumur memperlihatkan visualisasi dari bangun ruang tabung, dan bentuk wadah air visualisasi dari bangun ruang balok. Tabung adalah bangun ruang yang dibentuk dari 2 buah lingkaran yang sejajar dan sebuah persegi panjang mengelilingi kedua lingkaran yang disebut juga selimut tabung. Memiliki 2 buah rusuk lengkung dan tidak memiliki titik sudut. Bila 
diamati dari atas terdapat juga beberapa konsep bangun datar yaitu konsep lingkaran dan persegi panjang seperti yang terlihat pada Gambar 8 .

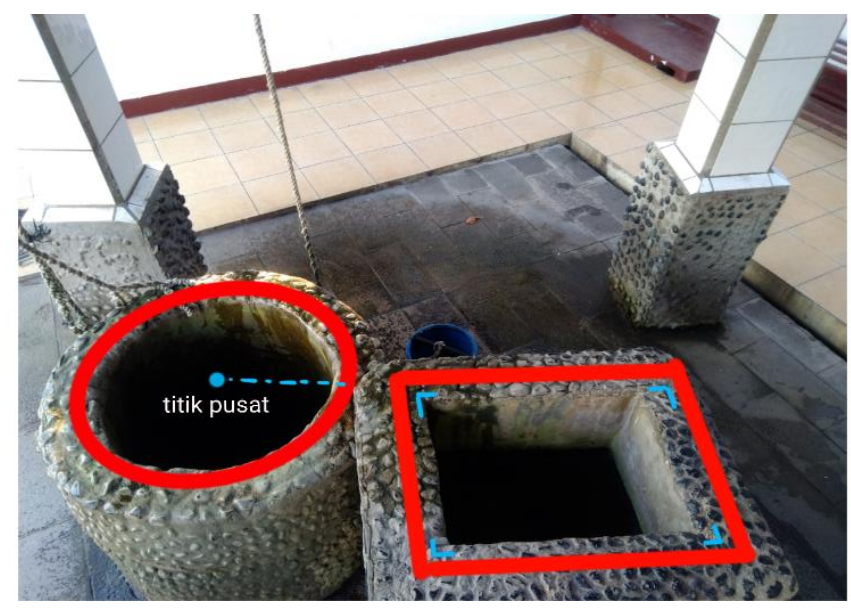

Gambar 8. Sumur dan wadah air dilihat dari atas

Lingkaran adalah kumpulan titik-titik pada garis bidang datar yang seluruhnya berjarak sama dari sebuah titik tertentu. Titik ini dapat disebut juga titik pusat lingkaran, sedangkan persegi panjang mempunyai 4 sisi, dengan sepasang sisi sejajar yang sama panjang, dan 4 titik sudut siku-siku.

Berdasarkan hasil penelitian dan teori yang menunjang maka dapat dikatakan bahwa bentuk bangunan masjid Al-Alam Marunda menerapkan beberapa konsep matematika yang terdiri dari konsep bangun datar, bangun ruang, konsep lingkaran, dan konsep transformasi refleksi.

Konsep bangun datar seperti segitiga siku-siku dan sama kaki pada penopang atap serambi, lingkaran dan persegi panjang pada sumur masjid, dapat diterapkan pada materi pembelajaran kelas VIII SMP yaitu teorema phytagoras segitiga siku-siku, dan lingkaran, serta materi pembelajaran kelas X SMA yaitu sifat sudut pada segitiga, segi empat, dan lingkaran.

Konsep bangun ruang seperti bentuk limas dengan alas persegi pada atap masjid, bentuk balok pada ruang inti dan wadar air, dan bentuk tabung pada sumur masjid, dapat diterapkan pada materi pembelajaran kelas 8 yaitu luas permukaan, volume, dan jaring-jaring bangun ruang sisi datar. Konsep tranformasi refleksi atau pencerminan pada pilar masjid dapat diterapkan pada materi pembelajaran kelas IX SMA tentang memindahkan semua titik dengan menggunakan transformasi geometri refleksi atau sifat pencerminan. Hasil temuan-temuan penelitian dapat dijadikan sebagai sumber belajar oleh guru seperti lembar kerja siswa (LKS) pada saat kegiatan dikelas ataupun menjadi sebuah objek pengamatan dalam menjelaskan bentuk-bentuk geometri yang ada dikehidupan sehari-hari.

\section{KESIMPULAN}

Berdasarkan hasil eksplorasi konsep matematika yang telah dilakukan, maka dapat disimpulkan bahwa Masjid Al-Alam Marunda merupakan bangunan bersejarah yang terdapat pembelajaran matematika berkaitan dengan budaya yaitu etnomatematika. Dengan dilaksanakannya inovasi etnomatematika pada objek Masjid Al-Alam maka ditemukan konsep matematika dalam bidang geometri 
karena pada dasarnya matematika bukan hanya mengenai rumus-rumus yang digunakan pada saat menjawab soal-soal, namun dapat diterapkan pada kehidupan sehari-hari. Demikian pembelajaran etnomatematika ini mampu mempelajari hal-hal yang berkaitan dengan kehidupan sehari-hari karena dapat memvisualisasikan secara nyata seperti adanya bentuk bangun datar, bangun ruang, sudut, bidang dan lainnya. Konsep-konsep geometri yang terdapat pada Masjid Al-Alam Marunda adalah konsep bangun ruang, bangun datar, konsep lingkaran, dan konsep transformasi refkleksi.

Konsep matematika khususnya geometri yang terdapat di Masjid Al-Alam dapat dijadikan sumber belajar matematika oleh guru, karena disekitar lingkungan kita dapat dimanfaatkan objek etnomatematika tersebut untuk melaksanakan pembelajaran yang inovatif. Selanjutnya penelitian ini dapat dikembangkan tentang perangkat pembelajaran matematika yang cocok berbasis cagar budaya atau bangunan bersejarah.

\section{REFERENSI}

Andarini, F. F., Sunardi, Lioni, A. M., Sugeng Didik, Pambudi, \& Erfan, Y. (2019). Etnomatematika Pada Alat Musik Tradisional Banyuwangi Sebagai Bahan Ajar Siswa. Kadikma, 10(1), 45-55.

D'Ambrosio, U. (1985). Ethnomathematics and Its Place In The History and Pedagogy of Mathematics For Learning of Mathematics. 5(1).

F. Sundari. (2017). Peran Guru Sebagai Pembelajar Dalam Memotivasi Peserta Didik Usia SD. Prosiding Diskusi Panel Pendidikan LPPM Unindra, 1(1), 60-76.

Hamzah, A., \&Muhlisrarini. (2014). Perencanaan dan Strategi Pembelajaran Matematika. Rajawali Pers.

M. Gay. (2015). Tugas dan Tantangan Guru: Membangun Kualitas Guru Menuju Pengembangan Pendidikan Bermutu. Edukasi - Jurnal Pendidikan, 13(2), 260-271.

M. Ja'far, Sunardi, dan I. A. (2014). “Pengembangan Perangkat Pembelajaran Berbasis Karakter Konsisten dan Teliti Menggunakan Pendekatan Realistic Mathematics Education ( RME ) pada Bab Kesebangunan dan Kekongruenan Bangun Datar Kelas IX SMP ( The Development of Mathematics Learning Aids Base. 29-35.

Pertiwi, I. J., \& Budiarto, M. T. (2020). Eksplorasi Etnomatematika Pada Gerabah Mlaten. Jurnal Cendekia: Jurnal Pendidikan $\quad$ Matematika, 4(2), 458-453. https://doi.org/10.31004/cendekia.v4i2.257

R. Purwasih. (2015). Peningkatan Kemampuan Pemahaman Matematis da Self Confidence Siswa MTs di Kota Cimahi Melalui Pembelajaran Inkuiri Terbimbing. Didaktik, 9(1), 16-25.

RACHMAWATI, I. (2012). Eksplorasi Etnomatematika Masyarakat Sidoarjo. MATHEdunesa, 1(1).

Rani, V. (2018). Etnomatematika Pada Candi Ratu Boko Sebagai Pendukung Pembelajaran Matematika Realistik. In Prosiding Seminar Nasional. (Ed.), Etnomatematika Pada Candi Ratu Boko Sebagai Pendukung Pembelajaran Matematika Realistik. (p. 1). UST Jogja. https://jurnal.ustjogja.ac.id/index.php/semnasmpd/article/viewFile/2998/1746

Rosa, D. C. O. \& M. (2011). Ethnomathematics: the cultural aspects of mathematics. Revisia 
Latinoamericana de Etnomatematica, 4(2), 32-54.

Sarwoedi, Marinka, D. O., Febriani, P., \& Wirne, I. N. (2018). (2018). Efektifitas Etnomatematika dalam Meningkatkan Kemampuan Pemahaman Matematika Siswa. Jurnal Pendidikan Matematika Raflesia, 3(2), 171-176.

Yulianti, M. (2016). Pengembangan Perangkat Pembelajaran Berbasis Etnomatematika dengan Pendekatan Saintifik untuk Pembelajaran Matematika pada Materi Geometri SMK Bidang Teknologi. Jurnal Pendidikan Matematika Dan Sains, 1, 10.

Yusuf, A. M. (2014). Metode Penelitian: Kuantitatif, Kualitatif, dan Penelitian Gabungan. Prenadamedia Group. 